\title{
PATRICK DANDREY, Dix leçons sur le premier recueil des "Fables" de La Fontaine (1668)
}

\section{Federico Corradi}

\section{OpenEdition}

\section{Journals}

\section{Edizione digitale}

URL: https://journals.openedition.org/studifrancesi/43848

DOI: 10.4000/studifrancesi.43848

ISSN: 2427-5856

\section{Editore}

Rosenberg \& Sellier

\section{Edizione cartacea}

Data di pubblicazione: 1 juin 2021

Paginazione: 214-215

ISSN: 0039-2944

\section{Notizia bibliografica digitale}

Federico Corradi, «PATRICK DANDREY, Dix leçons sur le premier recueil des "Fables" de La Fontaine (1668)»,

Studi Francesi [Online], 193 (LXV | I) | 2021, online dal 01 juillet 2021, consultato il 15 octobre 2022.

URL: http://journals.openedition.org/studifrancesi/43848; DOI: https://doi.org/10.4000/studifrancesi. 43848

Questo documento è stato generato automaticamente il 15 octobre 2022

\section{(c) (i) (9)}

Creative Commons - Attribuzione - Non commerciale - Non opere derivate 4.0 Internazionale - CC BYNC-ND 4.0

https://creativecommons.org/licenses/by-nc-nd/4.0/ 


\title{
PATRICK DANDREY, Dix leçons sur le premier recueil des "Fables" de La Fontaine (1668)
}

\author{
Federico Corradi
}

\section{NOTIZIA}

PATRICK DANDREY, Dix leçons sur le premier recueil des "Fables" de La Fontaine (1668), Paris, Hermann, 2019, 245 pp.

1 A quasi trent'anni di distanza dalla prima edizione della Fabrique des "Fables" (1991), Patrick Dandrey pubblica una nuova fondamentale monografia, che mette a frutto non soltanto la sua ininterrotta riflessione sul capolavoro di La Fontaine, ma anche la messe abbondante di dati forniti dai più recenti studi sul favolista. Rispetto al precedente saggio, la prospettiva è per un verso più limitata, per un altro più ampia: se la scelta è quella di concentrarsi sulla prima raccolta, la più fedele allo spirito esopico - l'autore passa così dall'approccio "teleologico", che considera i dodici libri come partizioni di un'opera unica, all'approccio "sequenziale", che vede nella prima raccolta un tutto in sé concluso -, per altro verso tutti gli "strati" dell'opera, tutti i principali nodi critici, vengono affrontati metodicamente in dieci lezioni. Ne risulta al contempo un percorso appassionante all'interno della raccolta e la più completa e aggiornata introduzione alle Fables oggi disponibile.

2 Come in ogni introduzione che si rispetti si parte dal contesto storico-culturale. La raccolta del 1668 si inquadra in primo luogo nel xvII secolo, visto come un lungo periodo di transizione tra le due grandi stagioni del Rinascimento e dell'llluminismo, ma si inserisce anche nei due decenni del cosiddetto classicismo francese, da cui La Fontaine trae il suo particolare "génie du tempérament", e nello straordinario biennio 1667-68, che ha visto nascere tanti capolavori. Mediante questi tre cerchi concentrici 
l'autore cerca di definire le condizioni che hanno reso possibile l'equilibrio instabile e fecondo su cui si basa la prima raccolta.

3 Inevitabile poi fare i conti con la filiazione esopica che, rivendicata nel modo più spettacolare nel paratesto del 1668, si rivela essere più fittizia che reale, non soltanto perché l'Esopo degli umanisti è un "auctor inventus" che fissa in una formula rigida i tratti ben più fluidi del genere favola, ma anche perché probabilmente La Fontaine ricorre di rado alla fonte "originale" accontentandosi in molti casi di una delle tante traduzioni-imitazioni in lingua francese che vedono la luce tra Cinque e Seicento. Inoltre, com'è noto, dalla "simplicité" del genere, il poeta prende esplicitamente le distanze in un celebre passo della préface che propone, seppure come un pis-aller, la formula alternativa della gaieté. Tra Esopo e La Fontaine c'è di mezzo naturalmente Fedro, la cui poetica ha senz'altro molti punti di contatto con quella del favolista francese. Tuttavia, confutando una recente ipotesi interpretativa avanzata da Boris Donné, Dandrey limita anche l'importanza del favolista latino nella genesi dell'opera: La Fontaine se ne distacca sia per la maggiore varietà delle soluzioni metriche che per il minor peso della componente satirico-politica. È piuttosto dalla préface di Lemaître de Sacy, recente traduttore delle favole fedriane, che attinge diversi spunti programmatici. La deferenza ostentata nei confronti dei modelli maschera insomma un'estrema disinvoltura nell'uso delle fonti, trasformate e contaminate a piacere in base alle esigenze del momento: lo dimostra la magnifica lettura di una delle favole più compiute della prima raccolta, Le Chat et un vieux Rat, dove lo straordinario virtuosismo stilistico consente a La Fontaine di reinventare, cucendoli insieme, due distinti motivi favolistici.

Prezioso anche il capitolo dedicato alla pedagogia delle Fables, che valorizza il rapporto del capolavoro lafontainiano da una parte con l'educazione del Delfino, dedicatario della prima raccolta, dall'altra con la tradizione scolastica dei progymnasmata. La Fontaine si rivela buon erede dei maestri di retorica (Ermogene, Aftonio, Elio Teone, ecc.) che da sempre hanno utilizzato la favola come esercizio di stile e di pensiero. Il confronto tra un passo del manuale di Aftonio e analoghe dichiarazioni programmatiche presenti nel paratesto delle Fables mostra l'entità del debito contratto da La Fontaine nei confronti di questa tradizione. Dandrey, insomma, prende molto sul serio la vocazione pedagogica delle Fables, pur stemperata dalla leggerezza della gaieté. Tuttavia, spiega anche come la favola lafontainiana, educata alla scuola della cultura mondana, non intenda rivolgersi solo ad un pubblico infantile, ma abbia più ampiamente l'obiettivo di «attirer [...] dans le piège d'une puérilité fictive et profonde» (p. 21) un pubblico adulto che non ha meno bisogno di questa ginnastica del pensiero.

5 Ampio spazio viene dedicato poi alla vexata quaestio dell'architettura della raccolta, di quell'ordine segreto che La Fontaine, adepto della mondana sprezzatura, sembra essersi ingegnato in ogni modo a dissimulare. Dandrey scommette sulla coerenza dell'opera e propone un'articolata ricostruzione del criterio tematico che secondo lui consente di ricondurre ad un percorso unitario l'apparente dispersività della raccolta. L'autore stesso riconosce, però, la parte di artificio inerente a questa operazione critica. Più convincente, a mio avviso, l'analisi interna del primo libro, ispirata al duplice modello delle artes memoriae e del giardino alla francese. Facendo interagire i tre criteri della forma, del registro e del tema, l'autore evidenzia l'equilibrio studiato tra simmetria e variazione, tra ordine e capriccio. Il libero accostamento di favole assai diverse non impedisce che emerga una coerenza di fondo basato su alcuni testi pivots che 
costituiscono altrettante pause nell'ideale promenade proposta al lettore e che aprono scorci e prospettive sugli altri testi. Ma ancora più significativa è l'alternanza, costante nella prima raccolta, di due paradigmi, le favole narrative, più vicine alla maniera dei Contes, e le favole iconiche, affini all'emblema. Le prime fondate sull'interpenetrazione costante tra récit e moralité, le seconde sul modello più rigido della decifrazione allegorica. Non si tratta certo di due modelli antitetici e nettamente distinguibili, ma di due poli tra i quali il favolista crea continue interferenze e contaminazioni.

Di grande interesse anche il capitolo dedicato all'allegorismo animale, tributario di una molteplicità di fonti, che vanno dai bestiari ai trattati di zoologia, dalla fisiognomica alla tradizione esopica. Dandrey mostra la rilevanza per il favolista di tutte queste tradizioni. Ma tali schemi interpretativi non hanno niente di rigido e consentono a La Fontaine di giocare liberamente con i codici senza esserne prigioniero. Soprattutto è il confronto con Perrault, con il suo bestiario ben più inquietante, a illuminare la specificità delle Fables, basate sul principio della trasposizione metaforica piuttosto che su quello della metamorfosi onirica. Tuttavia, l'ibridità costitutiva dei personaggi della favola gioca costantemente sull'interferenza e il décalage tra mondo umano e mondo animale, alimentando in modo decisivo la poetica della gaieté.

7 Al rapporto récit-moralité è dedicato l'ultimo capitolo, che punta a riscattare la morale delle favole dall'accusa ricorrente di piattezza. L'analisi esemplare della Cigale et la Fourmi mostra, al contrario, come anche le favole più semplici consentano letture a più livelli di profondità: gli elementari principi di prudenza pratica dispensati dal favolista nel più celebre degli apologhi celano infatti una riflessione ben più profonda, quasi prebergsoniana, sulla relatività del tempo.

Questa rapida rassegna dei temi affrontati nel libro non rende giustizia alla sua ricchezza. Dandrey alterna efficacemente la trattazione ampia e documentata di questioni generali, le raffinate analisi di testo e i confronti sempre pertinenti con autori contemporanei o di altre epoche, che illuminano di luce nuova i passi anche più noti del capolavoro di La Fontaine. L'autore prende posizioni nette e decise, spesso condivisibili, sui principali nodi problematici legati alla genesi e all'interpretazione delle Fables. L'elegante "sprezzatura" dello stile contribuisce in modo decisivo a rendere la lettura accattivante. 